\title{
SOUTHERN SUDAN REFERENDUM ON SELF-DETERMINATION Legal Challenges and Procedural Solutions ${ }^{1}$
}

\author{
Francesca Marzatico \\ Dr Francesca Marzatico was Technical Advisor to the Southern Sudan \\ Referendum Commission \\ e-mail: francesca.marzatico@gmail.com
}

\begin{abstract}
This study attempts to analyse the major challenges encountered in the organisation of the Southern Sudan Referendum on Self-Determination and how these challenges were addressed, enabling the referendum to take place in a peaceful environment, with a high degree of transparency and fairness. In doing so it aims to identify a few lessons which, though emerging from the particular experience of the Sudan, can be used as a general paradigm in future similar contexts. The Southern Sudan Referendum Commission had less than four months to prepare, organise and conduct the operations within a broad mandate conferred by the Southern Sudan Referendum Act, many sections of which lacked clarity. The interpretation and application of this law represented, in several instances, a serious challenge to the organisation of the referendum, adding complexity to a process already made difficult by time and operational constraints amplified by the size of the territory and the highly sensitive political environment characterised by mistrust among the partners in the Comprehensive Peace Agreement. The study begins with a brief introduction to the political and legal background of the referendum and of the Southern Sudan Referendum Commission, including its role and structure. It proceeds with an analysis of the legal and regulatory framework, aimed at identifying the main challenges to the process and the solutions found in order to allow the referendum to take place in a timely, peaceful and orderly manner.
\end{abstract}

1 The study has benefited from the critical views and experience of Hon Paolino Wanawilla Unango, Deputy Minister of Justice of the Republic of South Sudan, Commissioner at the Southern Sudan Referendum Commission and a member of the Joint Legal Committee which drafted the Referendum Act, who generously shared his experience and information about the SSRC's work with me and who unfailingly gave his support to the organisation of the Southern Sudan Referendum on selfdetermination. 


\section{INTRODUCTION}

In January 2011, almost unexpectedly, the referendum on the self-determination of Southern Sudan took place in a peaceful and orderly manner, allowing the people of Southern Sudan to choose their status and consequently the future of the country through the exercise of their right to self-determination as recognised by the Comprehensive Peace Agreement (CPA).

The context in which the referendum was organised was extremely complex and required that attention be paid to different aspects of the process, which had to take into account many factors. The political environment was sensitive and characterised by mistrust between Northern and Southern Sudan exacerbated by non-compliance with the deadlines set in the CPA and the consequent dysfunction of those provisions of the agreement aimed at making unity attractive.

The expectations of the people of Southern Sudan, who had striven for the recognition of their right to self-determination since their independence from the British government, meant they tolerated the non-compliance with the CPA deadlines in order to have the referendum go ahead.

There were logistical and operational challenges relating to the size of the territory and to the absence in Southern Sudan of means of communication and transportation in remote areas, the lack of infrastructure and the high illiteracy rate of the population. The time constraints related to the late enactment of the Southern Sudan Referendum Act (SSRA or 'the Referendum Act' or 'the Act') and the late appointment of the Southern Sudan Referendum Commission (SSRC or 'the commission'). The difficulties were augmented by the ambiguity of some of the provisions of the SSRA.

In spite of all these challenges the referendum, which was considered to be a 'remarkable operational and political achievement' (EUEOM 2011, p 5), took place 'on time and in a calm, peaceful and orderly environment' (EUEOM 2011, p 5), representing the 'genuine expression of the will of the electorate' (Carter Center 14 February 2011).

There are multiple reasons for this remarkable achievement - among them the strong commitment and support of all parties involved: the Referendum Commission, the CPA partners, the international community and the people of Southern Sudan. The SSRC was not left alone in this endeavour. It counted on the strong and effective technical, operational and logistical support provided by the international community, namely the United Nations, the International Federation of Electoral Systems (IFES), the European Union, coordinated by the United Nations Integrated Referendum and Electoral Division (UNIRED), ${ }^{2}$

2 UN Security Council Resolution 1919 mandates UNMIS to be prepared to play 'a lead role in international efforts to provide assistance, as requested, to support preparations for the referenda in 2011, including in consultation with those member states able and willing to provide support ...' 
'without whom the Referendum would not have taken place on time, and in the efficient manner that it did' (EUEOM 2011, p 7).

This support did not undermine the SSRC's ownership of the process. The commission's independence - vis à vis national and international partners - has contributed to increased trust in the process. Financial support was provided by the CPA's partners and the international community and the process was also assisted by the Southern Sudan 2011 Taskforce, established by the Government of Southern Sudan (GOSS), which, inter alia, assisted in the campaign to raise awareness about the referendum, and by the attitude of Sudanese people, who avoided confrontational situations and allowed the referendum to take place in a peaceful environment.

Moreover, in the process of organising the referendum the tribal divisions and animosities among different political personalities in Southern Sudan were overcome, showing the unity and determination of the Southern Sudanese people to express their will to exercise their right to self-determination.

In order to understand the expectations and implications of the referendum a brief historical overview of the right to self-determination for the people of Southern Sudan, its formulation and interpretation in the CPA, together with a short description of the political context, will be provided in the following pages. The study will then continue with a description of the structure and functions of the SSRC, the Southern Sudan Referendum Bureau (SSRB) and the Taskforce, highlighting the operational challenges the commission encountered in organising the referendum.

Particular attention will be paid to the time constraints, not only in consideration of the short timeframe for the organisation of the process, but also as a factor which might have undermined the legitimacy of the process, with reference to the SSRA provisions legally scheduling some of the referendum activities. This overview will provide the information necessary to an understanding of the difficult circumstances in which the referendum took place. The main legal challenges encountered in the implementation of the Referendum Act will be outlined, together with the solutions (when found) adopted by the SSRC to overcome them and ensure the organisation of a fair, transparent and peaceful process. The study will conclude by drawing lessons learned from the Southern Sudan referendum that may be applied in similar situations.

The CPA, signed on January 2005 between the government of Sudan and the Sudanese People's Liberation Movement/Army (SPLM/A), ended more than two decades of civil war in the Sudan. Also known as the Naivasha Agreement, it was the culmination of more than three years of negotiations, resulting in a set 
of agreements ${ }^{3}$ that provided for a new political map of the Sudan, creating, inter alia, conditions for power sharing between the two signatories for an interim period of six years, ending on 9 July 2011.

During the interim period the CPA mandated power- and wealthsharing arrangements aimed at ending decades of the political and economic marginalisation of the South and guaranteeing it representation in a government of national unity (GNU) proportional to its population.

\section{THE RIGHT TO SELF-DETERMINATION}

The CPA established both the GNU and a national legislature in Khartoum, assigning one-third of posts in those institutions to the historically underrepresented Southern Sudanese. It also established the GOSS in Juba, financed with half the revenue from Southern oil. Most importantly, the CPA recognised the right of the people of Southern Sudan to self-determination, 'inter alia, through a referendum to determine their future status' ${ }^{4}$

The long path to self-determination for Southern Sudan dates back to the struggle for the independence of the Sudan from the colonial power. In 1953 Sudan's first self-governing Parliament was elected and discussions began about federalism as a constitutional solution for the country.

During the conference of 1954 to discuss the future of Sudan in general and the political future of the South in particular, Southern leaders voted for

3 The process resulted in the following agreements (also referred to as protocols):

Chapter I: The Machakos Protocol, signed in Machakos, Kenya, on 20 July 2002, agreement on broad principles of governance.

Chapter II: The Protocol on Power Sharing, signed in Naivasha, Kenya, on 26 May 2004.

Chapter III: The Agreement on Wealth Sharing, signed in Naivasha, Kenya, on 7 January 2004.

Chapter IV: The Protocol on the Resolution of the Conflict in Abyei Area, signed in Naivasha, Kenya, on 26 May 2004.

Chapter V: The Protocol on the Resolution of the Conflict in Southern Kordofan and Blue Nile States, signed in Naivasha, Kenya, on 26 May 2004.

Chapter VI: The Agreement on Security Arrangements, signed in Naivasha, Kenya, on 25 September 2003.

Annexure I: The Permanent Ceasefire and Security Arrangements Implementation Modalities and Appendices, signed in Naivasha, Kenya, on 30 October 2004.

Annexure II: The Implementation Modalities and Global Implementation Matrix and Appendices, signed in Naivasha, Kenya, on 31 December 2004, which includes, inter alia, The Implementation Modalities of the Machakos and Power Sharing Protocols.

The final, Comprehensive Peace Agreement signed on 9 January 2005, marking the commencement of the interim period.

4 Article 1.3 of the Machakos Protocol reads as follows:

'... the people of South Sudan have the right to self-determination, inter alia, through a referendum to determine their future status'. In this Protocol the parties agreed on a broad framework, setting forth the principles of governance, the transitional process and the structures of government as well as on the right to self-determination for the people of South Sudan, and on state and religion. 
independence from Egypt on condition that the independent country adopted a federal system, with an autonomous state in the South. In case of failure to do so, they believed, the South should have the right to self-determination, including the option of complete independence from the North (Johnson 2004, p 27).

Northern parties in the parliament in Khartoum, believing the call for federalism to be a tactic to achieve self-determination for the South, refused to adopt a federal system. ${ }^{5}$ Faced with the rejection of federalism by a parliamentary committee largely composed of northerners, the South started an insurgency to gain independence from the North. The insurgency, which begun with a military mutiny in Torit in 1955, became a movement for the liberation of Southern Sudan, which would become known as the Southern Sudan Liberation Movement (SSLM).

The rebellion ended with the Addis Ababa Agreement, signed on 27 February 1972 between the central government of the Sudan and the SSLM and granting the Southern Sudan region self-governing powers. According to the agreement the provinces of Western Bahr-el-Ghazal, Equatoria and Upper Nile constituted a self-governing region within Sudan known as Southern Region, with its own legislative and executive organs elected by southerners. ${ }^{6}$

The agreement was embodied in the Self-Government Act in March 1972 and incorporated in the Permanent Constitution of 1973. However, it was unilaterally abrogated in 1983 by then-President Jaafar Nimeiri, who, with his Republican Order Number One, divided the South in three regions, putting an end to the Southern Regional Autonomous Government (Collins 2008, pp 137-145).

The abrogation resulted in a mutiny in the national army led by southerners in Bor and Ayud, which eventually developed into the SPLM/A, which was distinguished from the SSLM in that it did not fight for the independence of the South but for the building of a New Sudan, a federation with a central government that would combat racism and tribalism (Collins 2008, p 143).

In 1997 a number of Southern armed groups, including the Southern Sudan Independent Movement / Army (SSIM / A), which split from the original SPLM / A, signing the Khartoum Peace Agreement ${ }^{7}$ with the Government of Sudan, which stipulated in General Principle $n 4$ that ' $\mathrm{t}$ ] he people of South Sudan shall exercise the right of self-determination through a referendum'.

5 For a more exhaustive analysis of the history of the conflict between North and South Sudan see Collins 2008 and Johnson 2004, pp 26-27.

6 For detailed information about the agreement, see Shinn 2004, pp 239-59.

7 Sudan's Khartoum Peace Agreement was signed on 21 April 1997 by central government and a number of Southern armed groups, led by Riak Machar. The demand for self-determination figured in the many subsequent rounds of peace negotiations, but it was not until 1997 that the government formally accepted it, in the Khartoum Peace Agreement, which was never implemented. For more information see Nyama 2000, pp 198-203; Johnson 2004 p 36 and Collins 2008, pp 245-50. 
The historical background of the right to self-determination of Southern Sudan, described briefly above, explains why the SPLM / A considered the issue to be one of the 'red lines' during the negotiation of the Machakos Protocol (Johnson 2011, pp 49-50).

The right to self-determination for all people is recognised by the International Covenant on Civil and Political Rights (ICCPR), in line with the principles and purposes of the United Nations (UN) Charter. Its realisation is considered to be an essential condition for the effective guarantee and observance of individual human rights. Self-determination is linked to the core concept of democracy, understood as the right to choose the political status which allows the economic and cultural development of the society, and the right to participate in the decisionmaking process. There are different degrees of self-determination, ranging from political emancipation within the sovereignty of the state through various forms of internal self-determination, to secession, which is only recognised in exceptional circumstances. ${ }^{8}$

The recognition of 'self-determination' in Article 1.3 of the Machakos protocol raised issues of interpretation relating to the use of the expression inter alia with reference to the mechanisms through which such a right could be exercised. Two interpretations are of particular interest. The one mostly favoured by those supporting the unity of Sudan considers the referendum to be the only mechanism through which the right to self-determination can be exercised

According to this interpretation, since external self-determination is an exception to the principle of sovereignty it may be exercised only in accordance with the conditions under which it has been recognised. In terms of this perspective the exercise of the right to self-determination for the people of Southern Sudan, was limited by and linked to the CPA, with the consequence that it would expire at the end of the interim period.

On the other hand, the interpretation supported by those advocating the secession of Southern Sudan regards the referendum as merely one of the mechanisms through which such a right can be exercised. According to this perspective the use of the expression inter alia recognises the existence of other means for the exercise of the right to self-determination, not spelt out in the agreement, which could have been used if no referendum was held. According to this interpretation a unilateral declaration of independence by Southern

8 Self-determination is a complex right, entailing both an 'internal' and an 'external' form.

The right can be conceptualized as a sliding scale of different levels of entitlement to political emancipation, constituting various forms of [internal self-determination] up to the apex of the right, the right of [external self-determination], which vests only in exceptional circumstances. Different 'peoples' are entitled to different levels of self-determination. 
Sudan would not have been considered to conflict with international law if the referendum had not taken place in the time set forth in the CPA.

A posteriori it can be argued that the latter interpretation, while strengthening the position of the supporters of secession, probably inhibited any attempt to jeopardise the referendum process in order to maintain the unity of the Sudan.

What follows is an analysis of the major challenges encountered by the commission in the organisation of the referendum on self-determination and the way these challenges were dealt with to enable the referendum to take place in a peaceful environment and to attain a high degree of transparency and fairness.

\section{THE TIMEFRAME}

In accordance with Article 2.5 of the Machakos protocol, six months before the end of the six-year interim period

there shall be an international monitored referendum, organised jointly by the GOS and by the SPLM / A for the people of Southern Sudan to: confirm the unity of the Sudan by voting to adopt the system of government established under the Peace Agreement, or to vote for secession.

The same provision is contained in Article 222 of the Interim National Constitution (INC) and in Article 11 of the Interim Constitution of Southern Sudan (ICSS). ${ }^{9}$

The referendum on self-determination represented a milestone for the implementation of the CPA. The Naivasha agreement set ambitious deadlines, including those considered to be essential for the organisation of the referendum itself, many of which were not respected. ${ }^{10}$ This augmented mistrust among CPA partners and contributed to the creation of a sensitive political environment.

As stipulated in the CPA the SSRA should have been issued at the end of the third year of the interim period and the SSRC appointed immediately afterwards; voter registration should have started at the beginning of the sixth year of the

9 Article 222 of the INC and Article 11 of the ICSS stipulate as follows:

Six months before the end of the six-year interim period, there shall be an internationally monitored referendum, for the people of Southern Sudan organised by the Southern Sudan Referendum Commission in cooperation with the National Government and the Government of Southern Sudan,

(2) The people of Southern Sudan shall either:

(a) confirm unity of the Sudan by voting to sustain the system of government established under the Comprehensive Peace Agreement and this Constitution, or

(b) vote for secession.

10 As explained below, both the adoption of the Southern Sudan Referendum Act and the establishment of the Referendum Commission took place later than prescribed in the CPA. 
interim period and ended three months before voting (ss 1(a), (b) and (c) of the Implementation Modalities of the Machakos and Power Sharing Protocols).

The same timeline was reflected in the INC and the ISCC. ${ }^{11}$ Nevertheless, the SSRA was enacted only at the end of 2009, while the SSRC was appointed at the end of June 2010, sworn in on 6 July 2010, seven months after the National Assembly's passage of the SSRA, and became operational only in September 2010 when an agreement was reached among the commissioners on the appointment of the secretary general. The secretary general was nominated on 2 September and appointed by the presidency on 14 September.

The time factor was one of the major challenges in the organisation of the referendum, generating new challenges or aggravating existing ones. The newly appointed SSRC was left with less than four months to organise its structures and set up its offices, issue the regulatory framework for the implementation of the SSRA, train the staff, conduct the voter registration, procure the relevant referendum material and distribute it to the referendum centres, prepare the timeline for the process, set up ad hoc committees as provided by the Referendum Act, conduct voter education and organise a media campaign, to mention only some.

The tight deadlines had not only operational but legal implications, as some of the activities to be implemented by the SSRC were already scheduled in the SSRA, with the consequence that their violation was foreseen as jeopardising the legitimacy of the process. Attempts to affect the legitimisation of the referendum were made throughout the process, in particular, the cases filed before the Constitutional Court against the SSRC focused partially on the disrespect by the commission of the deadlines set out in the SSRA, such as s 32.1, which related to the publication of the final voters' register.

\section{THE SOUTHERN SUDAN REFERENDUM COMMISSION}

The SSRC, established on 30 June 2010, six months after the Referendum Act was enacted and with its headquarters in Khartoum, was composed of nine members, all Sudanese (five from the South, four from the North), including the chairman

11 Article 220 of the INC stipulates that:

(1) ASouthern Sudan Referendum Act shall be promulgated by the National Legislature at the beginning of the third year of the interim period.

(2) The Presidency shall, as soon as Southern Sudan Referendum Act is issued, establish the Southern Sudan Referendum Commission.

Similarly, Article 10 of the ICSS states that:

(1) ASouthern Sudan Referendum Act shall be promulgated by the National Legislature at the beginning of the third year of the Interim Period.

(2) The Presidency of the Republic of the Sudan shall, as soon as the Southern Sudan Referendum Act is promulgated, establish the Southern Sudan Referendum Commission. 
and the deputy chairman, who perform their duties on a full-time basis. The commissioners were appointed by the president of the republic with the consent of the first vice-president and the approval of the National Legislative Assembly (SSRA s 10(1)), with their membership set to expire at the end of the interim period (SSRA s 10(3)).

The SSRC was responsible for the overall management of the referendum, including developing all rules, regulations and policies relating to the conduct of the referendum and managing the referendum in 'other locations' - that is, every referendum centre established by the commission outside Southern Sudan, in areas densely populated by the people of Southern Sudan, namely, Northern Sudan, Ethiopia, Kenya, Uganda, Australia, Britain, the USA, Canada and Egypt.

The SSRA Act also provided for the establishment of a Southern Sudan Referendum Bureau (SSRB or 'the bureau') in Juba, comprising four members appointed by the commission acting on recommendations from the deputy chairperson of the commission (who was also chairperson of the bureau). Its main role was to organise operations in the Southern Sudan and to coordinate activities between the SSRC and the high committees, supervising their work in order to ensure the 'fairness and transparency of the referendum process' (s 18 (3)(b)) and to carry out all referendum related activities in the counties.

Furthermore, to support the organisation of the referendum, as mandated by the Act, the government of Southern Sudan established the Southern Sudan 2011 Taskforce. Based in Juba and without being a part of the referendum process itself, the taskforce served as the coordinating body and guiding entity for the preparation of the referendum and the post-referendum period for Southern Sudan, ensuring that concrete action would be taken by relevant institutions at all levels of government in the preparation of the referendum.

The taskforce had the role of facilitating coordination within the government and with external partners over issues of critical importance to the effective management of the referendum and the post-referendum period. It also provided logistical support to the referendum centres and conducted a voter awareness campaign in Southern Sudan.

As anticipated, the political environment of the referendum was highly sensitive and governed by mistrust between partners in the CPA.

There were many attempts to influence the SSRC and to jeopardise its work. One of the examples was discussions about the appointment of the secretary general, which took more than two months. In order to maintain its independence and impartiality the commission found itself having to resist attempts by the CPA partners to interfere. It also had to manage its relations with the international community, providing both technical assistance and funding, to ensure its 
ownership of the process and to minimise the criticism, mostly coming from the $\mathrm{NCP}$, of international influence on the commission. ${ }^{12}$ In certain instances this led to the adoption of confrontational positions with the international community, which, in some cases, resulted in delays in preparations for the referendum. ${ }^{13}$

Despite provisions in the CPA stipulating the establishment of an ' ... ad-hoc Commission to monitor and ensure accuracy, legitimacy, and transparency of the Referendum as mentioned in the Machakos Protocol on Self-Determination for the People of Southern Sudan, which shall also include international experts' (Chapter II, Art 2.10.1.5 CPA) the SSRC comprised only Sudanese members supported by international advisers. ${ }^{14}$

The presence of international advisers in the bureau was not as restricted as it was in the commission's headquarters and the SSRB relied extensively on international technical advisers to organise the operations of the referendum, distribute material to referendum centres, communicate with state high committees and sub-committees and provide other logistical support.

The SSRC faced several challenges at its inception. Among these were problems of hiring referendum staff at such short notice, especially in Southern Sudan, where the high illiteracy rate among the older generation amplified this difficulty. Most of the staff lacked electoral expertise and time constraints made it difficult to provide them with adequate training. These challenges generated further delays in setting up operations, making decisions and issuing regulations or other legal opinions. These constraints were overcome by the commitment of most of the staff of the SSRC, supported by the well-coordinated and effective technical assistance provided by the international advisers.

12 On several occasions the international community has been accused of manipulating, influencing and taking over the work of the commission. In some cases the accusations came from the commission itself. Pressure from the international community at the start of the referendum process highlighted some weaknesses of the commission. One example was the publication of the first timeline of the referendum process before the SSRC announced it in Khartoum.. Following this, the commission changed the timeline several times without sharing the information with its international partners. Eventually confidence between the international community and the commission was restored and the former was seen more as a partner than an antagonist.

13 Emblematic of this attitude of the SSRC was the chairman's resistance to approving the voter registration training manual which was prepared by international advisers with very little consultation with the SSRC.

14 In order to preserve the independence of the commission and to avoid further criticism from the NC, the commission hired only Sudanese staff and allowed only one international adviser to have office space on its premises in Khartoum, while the other international advisers, who had unrestricted access to the premises of the commission and to its staff, were not allowed to have an office in the building. 


\section{THE SOUTHERN SUDAN REFERENDUM ACT AND THE REGULATORY FRAMEWORK}

The SSRA, which was enacted on 30 December 2009, provided the basis for the organisation of the referendum. While some of its provisions, such as the date of polling, the referendum question and the role and structure of the SSRC, did not require interpretation some areas lacked clarity, were inconsistent and did not provide sufficient details about important aspects of the referendum (DRI July 2010).

It also conferred on the SSRC the power to regulate many aspects of the referendum and set ambitious deadlines which could not be met and which represented serious challenges to the legitimacy of the process. ${ }^{15}$

The difficulties relating to the interpretation, vagueness and lack of clarity of its provisions derive from the fact that the Referendum Act is the result of lengthy political negotiations between the NCP and the SPLM. Agreement was reached overnight about certain provisions as a political compromise between the parties, without due consideration of their effect on the organisation of the process, a problem, as outlined below, that augmented the challenges faced by the SSRC in the organisation of the referendum. ${ }^{16}$

\section{Voter eligibility}

The definition of who is entitled to vote was one of the main challenges in the organisation of the referendum. Lack of clarity in the Act, together with a lack of reliable data deriving from the census conducted in $2008,{ }^{17}$ made it difficult to estimate the number of individuals allowed to register and vote. Moreover, sections 27(3) and 27(4) of the Act differentiated between those eligible voters who could register and vote at any referendum centre in Southern Sudan or 'other locations' (s 27(3)) and those who could only register and vote in Southern Sudan (s 27(4)).

15 Section 32.1 of the Act required the final referendum register to be published three months before polling, while s34 required the commission to issue details of polling procedures two months before the start of the poll.

16 Some of these provisions related to the establishment of a minimum age of 40 years for members of the staff of high committees, sub-committees and referendum centres (s22 (2) and s23(4)) and provisions relating to the IOM's role in the organisation of the referendum in other locations (s 27 (3) and (4)). The content of these provisions are analysed below.

17 According to the Statistical Yearbook for Southern Sudan, 2009, prepared by the Southern Sudan Centre for Census Statistics and Evaluation, the population of South Sudan at the time of the 2008 census was 8260490 , of which 4213041 were above the age of 17. The results of the census have been contested by the Goss as failing to reflect the exact size of the population of Southern Sudan and of Southern Sudanese in Northern Sudan. 
The interpretation of these provisions in order accurately to determine the number of potential voters had important operational implications which affected, among other factors, the number of voter registries and ballot papers to be printed, the number of referendum centres to be opened in Southern Sudan and 'other locations' and the number of referendum centre staff.

According to s 25 of the SSRA

[t]he voter shall meet the following conditions:

1. [be] born to parents both or either of whom belongs to any of the indigenous communities residing in Southern Sudan on or before the $1^{\text {st }}$ of January 1956, or whose ancestry is traceable to one of the ethnic communities in Southern Sudan,

or,

2. permanently residing without interruption, or whose parents or grandparents are residing permanently, without interruption, in Southern Sudan since the $1^{\text {st }}$ of January 1956;

3. have reached 18 years of age;

4. be of sound mind;

5. registered in the Referendum Register.

While in Regulation 8(2) and (3) of the Voter Registration Regulations the SSRC clarified that a person could be registered only if he or she had reached 18 years of age at the time of registration, and confirmed the existence of a general presumption of soundness of mind unless proved otherwise, the definition of Southern Sudanese remained unclear. The Voter Registration Regulations repeated the provisions of the Act without clarifying issues related to the identification of the indigenous communities and of Southern $\operatorname{Sudan}^{18}$ and the criteria for defining 'residence without interruption'. ${ }^{19}$

18 Aly Verjee, former deputy director of the Carter Center in Sudan, in his paper 'Race Against Time: The Countdown to the Referenda in Southern Sudan and Abyei', correctly argues ( $\mathrm{p} 20$ ) that

[t]he SSRC's refusal to compile a list of ethnic groups may well be wise. Defining eligibility on the basis of membership of an ethnic group would have unintended divisive effects in Southern Sudan and its borderlands. In attempting to satisfy the short-term aims of the referendum, it would establish ethnicity as the primary criterion of citizenship, opening the possibility of disputes at every level over the definition of ethnicity.

19 The SSRC, in the Legal and Procedural questions and Answers of 6 October 2010, specified that the criterion for residency is not linked to a length of time but to the intention to establish one's centre of interest in a certain place (domicile of origin). This can be proved in court. 
The definition of Southern Sudanese in the Act differs from that in Article 9(3) of the ICSS, which defines a person from Southern Sudan as:

(a) any person whose either parent or grandparent is or was a member of any of the indigenous communities existing in Southern Sudan before or on January 1, 1956; or whose ancestry can be traced through agnatic or male line to any one of the ethnic communities of Southern Sudan; or

(b) any person who has been permanently residing or whose mother and/or father or any grandparent have been permanently residing in Southern Sudan as of January 1, 1956.

The Act represents a step forward with respect to gender equality as it makes no reference to the 'agnatic or male line', recognising the right to register and vote of southerners 'whose ancestry is traceable to one of the ethnic communities in Southern Sudan'. ${ }^{20}$ On the other hand, in both documents the use of the terms 'ethnic' and 'indigenous' communities creates confusion around the definition of Southern Sudanese. Currently there is no official list of ethnic and indigenous communities, although the initial draft of the $\mathrm{ICSS}^{21}$ contained a tentative list, an attempt that was aborted in the final draft. ${ }^{22}$

The commission again addressed the lack of clarity about the definition of Southern Sudanese under ss 25(1) and 25(2) three weeks before the beginning of voter registration. In a statement issued on 21 October 2010 the SSRC identified three categories of eligible voters:

1. [Group 1:] Voters who belong to one of the indigenous ethnic communities residing in the Southern Sudan (on or before 1 January 1956).

20 The gender equality perspective was introduced by women who participated in the Joint Legal Committee which drafted the SSRA. Nevertheless, it has been reported that at some referendum centres individuals whose father did not belong to one of the communities of Southern Sudan were not allowed to register, showing how the importance of the agnatic or male line is rooted in the Southern Sudanese communities and related customary law.

21 www.gossmission.org/goss/images/agreements/interim_constitution_southsudan_2005.pdf

22 Indigenous groups are the original inhabitants of a territory or region, especially before the arrival and intrusion of a foreign and possibly dominating culture. They represent the native ethnic groups, whose members share a cultural identity that has been shaped by their geographical region. Their right to self-determination may be materially affected by later-arriving ethnic groups. An ethnic group is a group of people whose members identify with each other through a common heritage, often consisting of a common language, a common culture (frequently including a shared religion) and an ideology that stresses common ancestry or endogamy (Seidner 1982, pp 2-3). 
2. [Group 2:] Voters who trace their ancestry to one of the indigenous ethnic communities in Southern Sudan, but have not resided permanently in the South (without interruption) before or since January 1956.

3. [Group 3:] Voters who do not belong to one of the indigenous ethnic communities in Southern Sudan but they or their parents or grandparents have resided permanently in the South (without interruption) since 1 January 1956.

According to this interpretation of sections 25(1) and (2), which does not differentiate between indigenous and ethnic communities, only voters belonging to group 1 were allowed to register and vote at any referendum centre whether in the South or in 'other locations'. Voters belonging to groups 2 and 3 could only register and vote in Southern Sudan, where they could be identified as Southern Sudanese by their communities of origin. ${ }^{23}$

The commission's interpretation met with the agreement of all parties involved in the referendum process and clarified a very controversial issue. None of the complaints received by the SSRC challenged the interpretation; nor did the Constitutional Court cases filed against the SSRC. Complaints and cases focused on the concrete application of the commission's interpretation, such as the right of Abyei residents to register and vote and, in particular, that of the Ngok Dinka of Abyei. ${ }^{24}$

Chapter IV of the CPA conferred upon the Abyei area ${ }^{25}$ a special administrative status under the institution of the presidency of the Sudan, by which residents of the area are dual citizens of both Western Kordofan in Northern Sudan and

23 The fact that the Act does not contain provisions relating to the spouses of Southern Sudanese stresses how the exercise of the right to self-determination is left to the ethnic and indigenous communities of origin in Southern Sudan.

24 Clarification on the participation of Dinka from Abyei in the Southern Sudan Referendum on SelfDetermination was also requested by international and local observer organisations.

25 The CPA defines Abyei as 'the area of the nine Ngok Dinka chiefdoms transferred to Kordofan in 1905'. Abyei is further considered a 'bridge between the north and the south, linking the people of Sudan'. The CPA gave the task of defining and demarcating the boundaries of Abyei to the Abyei Boundaries Commission (' $A B C$ '). The $A B C$ 's report was, however, contested, and the final delineation of Abyei was concluded in the Final Award of Arbitration in the Permanent Court of Arbitration at The Hague. The award established that Abyei encompasses a specific territory, populated by the Ngok Dinka, which was transferred to the Northern State of Kordofan in 1905. The southern boundary of Abyei is the 1956 border between Bahr el Ghazal and Kordofan. For additional details see Permanent Court of Arbitration 22 July 2009. 
Bahr el Ghazal in Southern Sudan, with representation in both state legislatures. ${ }^{26}$ The CPA also recognised the right of the residents of Abyei to self-determination through a referendum which was supposed to take place simultaneously with the Southern Sudan referendum. In the Abyei referendum residents of Abyei were supposed to decide either: a) that Abyei retain its special administrative status in the North or b) that Abyei be part of Bahr-el-Ghazal. ${ }^{27}$

It is unclear either from the CPA or from the Act whether residents of Abyei could also participate in the Southern Sudan referendum.

The commission did not issue any specific statement on the participation of the Dinka Ngok of Abyei in the Southern Sudan referendum but, in its answer to complaints and to requests from international observers for clarification, it highlighted that being a resident of Abyei was not a criterion of eligibility for the Referendum of Southern Sudan..$^{28}$ For this reason, no referendum centres were established in Abyei. Nevertheless, if Dinka Ngok from Abyei met the eligibility criteria provided for in s 25 of the Referendum Act they could register and vote in the nearest referendum centre in either Northern or Southern Sudan. ${ }^{29}$

\section{Proof of voter's identity}

The Referendum Act is not clear about the requirements for proof of identity for the purpose of voter registration (VR).

Section 26 of the Act required written documentation. In cases where the person concerned did not possess an identification document or in cases in which there were doubts about the authenticity of the documentation provided oral testimony was required from the chief of the community to which the person belonged.

Section 28 of the Act is, however, more restrictive, allowing only written documentation as proof of identity. ${ }^{30}$

The SSRC Voter Registration Regulations 2010 (hereinafter 'Voter Registration Regulations'), clarified the above by providing a list of documents considered as

26 CPA, Abyei Protocol Article 1.2.1 'Residents of Abyei will be citizens of both Western Kordofan and Bahr-el-Ghazal, with representations in the legislatures of both'.

27 CPA, Abyei Protocol Article 1.3.

28 The commission explained its position in relation to the eligibility of Ngok Dinka from Abyei in a response to the Carter Center on 5 January 2011.

29 In the Agok Declaration of 2003 (Preamble Part I(A), I(E), 2-7 June) the Ngok Dinka declared that they were included within the polity of Southern Sudan and that they 'are part and parcel of Southern Sudan'.

30 Section 28(2)(a) of the Act stipulates that anyone who 'possesses an identification document or a certificate authenticated by the Administrative Unit in the county or by the concerned local and traditional authorities as the case may be' may register in the referendum registry. 
proof of identity (Regulation 10) ${ }^{31}$ and allowing the oral testimony of the chief or sultan of the village (referred to below as 'identifiers') both as a proof of identity and as a verification of documents listed in Regulation 10 when the chief of the referendum centre $(\mathrm{RC})$ has doubts about their authenticity.

The list provided in Regulation 10 was not exhaustive and during the voter registration period, following requests from both eligible voters and the chief of the commission, the commission extended the list.

Both the Act and the Voter Registration Regulations are silent about the number of identifiers per referendum centre and about their selection and assignment. During the voter registration period the SSRC received complaints about the integrity and relevance of identifiers in some referendum centres. According to the allegations identifiers did not represent all communities in the area in which the referendum centre was situated. Identifiers were removed and replaced in those centres where allegations about their integrity and absence of links with the community were found to be reasonable.

\section{Objections to and appeals against voter registration}

The Act provides for complex procedures in relation to objections (s 30) and appeals (s 31) at the end of the voter registration period in cases of corrections to or cancellations on the voter registry. Section 30(1) of the SSRA confers the right to object upon any 'registered voter in a referendum centre' who wants 'to correct the erroneous information or data regarding his/her registration or object to the registration of another person if $s$ /he is: a) dead, b) left the County to another location for good, c) does not meet the voter's eligibility requirements or, d) does not meet the registration requirements'.

31 Regulation 10 of the Voter Registration Regulations provides a list of documents that may be used for identification purposes, allowing also the use of expired documents:

(1) Identification of voters shall be proved by any of the following:

(a) Nationality Certificate;

(b) Identity Card;

(c) Sudanese Passport;

(d) Birth Certificate;

(e) Driving Licence;

(f) Identification document issued by the United Nations High Commissioner for Refugees;

(g) Certificate issued by the local government authority or traditional authorities as the case may be;

(h) Oral testimony by a concerned county official or dignitary of the concerned community.

(2) For the purpose of registration any of the aforementioned documents shall be considered as valid proof of identification even if expired. 
The Act does not provide remedies for individuals who have been denied registration. The Voter Registration Regulations simplified the objections procedures contained in s 30 and, given the silence of the Act about such remedies, introduced Regulation 17 . These procedures, to take place only during the voter registration period, entailed a petition to the consideration committee in the centre involved, thereby expanding the mandate of the consideration committees beyond the provision of the Act, which mandated these committees only to decide on complaints from registered voters during the objection period.

The choice of the commission, although in line with international standards of democratic participation, generated more confusion about and inconsistencies in the objection and appeal procedures because it anticipated the establishment of the consideration committees before the registration period: a requirement which was impossible to meet. The SSRC issued the Voter Registration Regulations on 14 November, one day before registration started and it was impossible to set up consideration committees in time, with the consequence that at many referendum centres voters' rights to legal redress and effective protection were undermined.

Although it appears not to have affected many people, international observer reports recorded the fact that the delay denied some their right to appeal against their exclusion from the process. The failure to appoint the consideration committees in time was one of the complaints raised by those lawyers who brought cases against the Referendum Commission to the Constitutional Court.

\section{Requirements for the staff of the referendum centres}

Sections 22(2) and 23(4) of the Act, in specifying the number of members of the state high committees, the sub-committees and the referendum centre committees, sets out that the members must be at least 40 years old, a restriction that created serious operational and legal challenges.

In formulating the Act the legislators failed to foresee the operational implications of this provision and the difficulty of hiring so rapidly professional staff who could meet the age requirements. The problem was particularly challenging in Southern Sudan, where most people over 40 are illiterate. Moreover, the Act was inconsistent in imposing an age restriction only on some members of the SSRC staff - it was not imposed on the staff of the secretariat at the headquarters in Khartoum or at the bureau in Juba.

The commission recruited staff members without obliging them to prove their age and when the appointments were challenged the staff members were dismissed and replaced with others who met the age requirements. 


\section{Registration and voting in 'other locations'}

The Referendum Act allowed Southern Sudanese who met the eligibility criteria set out in s25 in combination with s 27(3) and s 27(4) to register and vote in Northern Sudan and in eight out-of-country voting locations-Australia, Canada, Egypt, Ethiopia, Kenya, Uganda, UK and USA. In doing so it aimed to ensure the broadest possible participation in the exercise of the right to self-determination of the Southern Sudanese diaspora (in the out-of-country locations) and of internally displaced Southern Sudanese (in Northern Sudan).

Section 27(5) of the Act conferred on the International Organisation for Migration (IOM) the responsibility to assist with the organisation of the procedures for registration, polling, sorting, counting and declaration of the results in other locations while, in relation to the out-of-country locations, s 27(6) mandates the chief of the referendum centre to coordinate with 'the IOM, with the participation of the country hosting the refugees and immigrants or expatriates from Southern Sudan in the procedures of registration, polling, sorting, counting and declaration of the results'.

The IOM was not consulted when this provision was drafted nor were the legislators aware of its operational and logistic capacity in the 'other locations'. When it came to the implementation of the Act the organisation had neither the operational nor logistic capacity necessary to carry out these duties in Northern Sudan. In addition, the absence of accurate figures for Southern Sudanese in 'other locations' and the lack of clarity about the eligibility criteria made it difficult to identify eligible voters.

In order to support the organisation of registration and voting in other locations and to release the IOM from some of the pressure it was decided that operations in Northern Sudan would have to be organised by the SSRC with the support of the UN Integrated Referendum and Electoral Division (UNIRED), while the IOM would assist in organising the referendum in the eight locations abroad.

According to s 27(1) of the Act, high committees had to establish referendum centres in the counties in Southern Sudan. In other locations, as provided for in s27(2), the commission was responsible for establishing such centres

provided that the number of the registered voters in each centre shall be at least 20,000. If the number is less than 20,000 in any location, a polling centre shall be open for them in the capital of the concerned state in Northern Sudan and the countries of emigration. 
In the brief time between the publication of the final voters' register and polling day (one day) it would have been operationally impossible for the commission to transfer all polling material from the registration centres to the capitals in cases in which the number of voters for that registration centre did not reach the mandated 20000 and then to inform voters about changes in the location of the polling station. This would have led to some potential voters being disenfranchised, thereby affecting the turnout, with consequences for the results and for the fairness and transparency of the process.

At the onset the SSRC had no intention of considering any options that differed from those prescribed in the Referendum Act. In its responses to critical operational questions from the international partners the commission confirmed its intention to 'maintain, for operational and logistic reasons, the criteria of establishing referendum centres in Northern Sudan, where there are at least 20000 estimated voters'. However, because the commission did not have accurate figures about the exact number and concentration of eligible voters in other locations it decided to 'open branch referendum centres for registration purposes'. In doing so, it decided to adopt the principle that allows voters to vote where they are registered. ${ }^{32}$

While procedures for registration and polling were the same in all locations there were different procedures for complaints related to the registration process in the locations abroad where the only remedy voters had at their disposal was to lodge objections with the consideration committees since they had no access to any competent court. ${ }^{33}$

\section{Publication of the final voters' register}

Given only four months to organise the referendum it was impossible for the SSRC to abide by the schedule set forth in the Act. One particular provision which represented a challenge was s 32(1), which prescribes that 'following the final revision and receipt of the results of objections, the Commission shall prepare the final referendum register and make it public three months prior to the start of polling'.

The breach of this provision was one of the complaints of those who went to the Constitutional Court to challenge the legitimacy of the entire referendum process.

32 Regulation 7 of the SSRC Regulations on Polling Sorting, Counting and Declaration of Results 2010 stipulates that 'Any registered voter shall vote in person at the same Referendum Centre where he registered'.

33 According to s2 of the Act, competent court '[m]eans the court determined by the President of the National Judiciary or the President of Southern Sudan Supreme Court, as the case may be, to be competent to rule on appeals and contraventions filed in accordance with the provisions of this Act'. 
The provision, whose rationale was the need to provide sufficient time for campaigning and for public inspection of the final voters' register, could not be respected in the time available. To comply with it the commission should have sought the approval of the CPA partners to postpone the date of the referendum. Without such agreement application of s32(1) would have jeopardised the exercise of the right to self-determination of people of Southern Sudan, violating the provisions of the CPA, INC and ICSS which recognise that right.

The commission requested the presidency to amend the provision, but received no response. ${ }^{34}$ Despite these problems the SSRC succeeded in organising the referendum and allowing enough time for voter registration and for objections to and appeals against the registration process.

\section{Voting procedures}

Section 34 of the Act provides that 'at least two months before the beginning of polling the commission should determine the schedule for polling procedure'. Here, too, the commission was unable to meet the deadline, issuing the regulations on polling, sorting, counting and aggregation of results on 29 December 2010, a few days before the commencement of polling, after the training manual for referendum centre staff on polling procedures had been printed and when the training of staff at the referendum centre had already taken place.

This delay created confusion among the staff because the regulations differed from the training manual in areas such as opening and closing times and the procedures for lodging objections during the polling process. Discrepancies were addressed by the SSRC staff and clarified through directives issued by the SSRC to the referendum centres.

Regulation 6 of the SSRC Regulations on Polling, Sorting, Counting and Declaration of Results 2010 defined as eligible to vote 'any person registered in the Final Referendum Register and in possession of his registration card'. Consequently, voters who lost their voter registration cards could not vote. During the poll this restriction was brought to the attention of the commission as disenfranchising voters who had lost their cards but could prove their identity and whose names appeared on the register at the referendum centre at which they claimed to have registered.

34 Verjee 2010, p 14, however, reports on a meeting on 29 August when 'the national presidency conceded this reality and agreed to the SSRC's proposal to ignore certain legal requirements of the SSRA, including the requirement to complete registration three months before the vote'. The commission did not mention that meeting or refer to it when discussing the challenges of the process. The three-month deadline for the publication of the final voters' register was always considered to have been one of the biggest challenges to the legitimacy of the process, a fact that has been confirmed in recent interviews with commission members. 
In order to address this issue the commission held an extraordinary meeting in Juba and issued a statement containing procedures allowing people who lost their voter registration cards to vote, thus allowing these voters to participate. ${ }^{35}$ Neither the contents of this statement nor the delay in issuing it was challenged during the polling period.

\section{Threshold}

Section 41(2)(a) of the Act requires that for the referendum to be valid at least 60 per cent of registered voters had to cast their votes. Normally referendum laws require voter turnout to be 50 per cent of registered voters. In the referenda on independence held in Montenegro ${ }^{36}$ and East Timor no specific turnout was required for their validity. The European Commission for Democracy through Law, better known as the Venice Commission, the Council of Europe's advisory body on constitutional matters, established in 1990, does not believe it is appropriate to lay down a quorum at all as it may encourage opponents to abstain in order to prevent a quorum being reached. ${ }^{37}$

Where a minimum voter turnout is required the voter registration process becomes as important as the vote, as does the accuracy of the voters' register, which provides the 100 per cent figure against which the turnout is calculated.

The threshold established for the referendum had its rationale in the negotiated nature of the Act. Nevertheless it represented an important challenge, especially because if the threshold had not been met it would have been difficult to justify any further claim for self-determination for Southern Sudan.

The regulations also clarified the interpretation of s 41(3), which, in stipulating that the referendum should be decided in favour of the option that secured a

35 The commission declared that voters who lost their cards, reported the loss to the police and obtained a police report to this effect could be allowed to vote upon verification that the report issued by the police contained both details of the voter identification document and the name/number of the referendum centre where the voter registered. If the voter's name was found on the referendum register, the voter in question had not already voted, and details contained in the police report corresponded to the relevant entries on the referendum registry the person was allowed to vote. A copy of the police report had to be kept at the referendum centre and a description of the fact that the voter was allowed to vote and the serial number of the voter's card was to be recorded in the referendum centre journal.

36 In the case of Montenegro the European Union required a 55 per cent majority for recognition of the results of the referendum, a requirement regarded by some Montenegrin leaders as 'undemocratic'.

37 In the explanatory memorandum to the Code of Good Practice on Referendums it is recommended that Council of Europe member states make no provision for quorums. The argument is that 'the existence of a turnout quorum (minimum percentage) encourages those who oppose the proposal contained in the referendum question to abstain rather than to vote against it'. 'Encouraging abstention or the imposition of a minority's view cannot be healthy for democracy. On the other hand, an approval quorum (acceptance by a minimum percentage of registered voters) may also be inconclusive. If a text is approved by a majority of voters without the quorum being reached, the majority will feel that they have been deprived of victory without an adequate reason.' 
simple majority of 50 per cent plus one of the total number of votes cast, did not mention that this majority should be calculated on the total number of valid votes cast. This generated confusion with reference to the meaning of s 66 of the Act, which stipulated that 'the option approved by the people of Southern Sudan by a majority of fifty percent plus one $(50 \%+1)$ of valid votes cast in the referendum ... shall be binding to all state institutions as well as all citizens of Southern and Northern Sudan'.

This confusion was clarified by the SSRC in the Regulations of Polling, Sorting, Counting and Declaration of results, in which Regulation 67 stipulated that: 'The Referendum Final Results shall be in favor of the option that secures the simple majority of fifty percent plus one $(50 \%+1)$ of the total number of valid votes cast for one of the two options.'

\section{Sorting, counting, aggregation and declaration of results}

Procedures for sorting, counting and declaring results were detailed in the regulations (for both Southern Sudan and other locations) in accordance with the provisions of the Act.

The regulations also detailed the procedures for aggregation and declaration of results, in line with the provisions of the Act. In Southern Sudan, once the results were declared at the referendum centres they were sent to the county sub-committees and from there to the state high committees. Both committees aggregated the results and sent a copy of their report to the bureau in Juba for verification and insertion into the database.

After the bureau declared the results for Southern Sudan they were sent to the commission in Khartoum for verification and aggregation for the declaration of the preliminary results. In Northern Sudan the aggregation was made by state referendum committees, while in the eight out-of-country voting locations this was done by the country office; in both cases the results were forwarded to the SSRC for verification.

The Act did not provide for procedures for objection during the sorting, counting and aggregation of results. Nevertheless, observers were allowed to assist at all stages of the process (including the uploading of information onto the databases in Juba and Khartoum). ${ }^{38}$

38 The data centres in Khartoum and Juba provided computers so observers could observe the process of aggregation of results. In cases of discrepancies among the reports received the results were quarantined for further investigation and verification. According to the quarantine report the bureau sent to the commission, of 2638 referendum centre results a total of 36 were quarantined. Of these 9 showed that clerical errors had been made at the data centre, 25 showed that registration forms had been incorrectly completed and in two cases the results form had been incorrectly completed. 
According to s 44 of the Act the final referendum results had to be declared within 30 days of the date polling ended. During this time all appeals had to be decided by the courts. ${ }^{39}$

In order to meet this deadline UNIRED set a capillary field structure to support the aggregation of results in Southern and Northern Sudan, while the IOM was responsible for supporting the aggregation of results in the out-of-country voting locations.

\section{OBSERVING THE REFERENDUM}

The presence and role of international and domestic observers is considered to be essential to the transparency of any democratic participation process. The Act contains ambiguous provisions about the role of observers and does not provide for the role of party agents as observers. The presence of latter is often considered to ensure political confidence in the polling and aggregation process.

Section 61(2) of the Referendum Act gives the commission, in coordination with the bureau, the power to constitute 'observation committees' from:
a) legal counsellors at the Ministry of Justice, Ministry of Legal Affairs and Constitutional Development of the Government of Southern Sudan as the case may be;
b) ex-public service employees or persons of the society, who are known for uprightness, truth and honesty;
c) civil society organisations, press and the media;
d) local, regional and international observers.

The commission decided not to create observation committees because time constraints would have made it difficult to identify adequate members in categories a) and b) who could participate in such committees in centres in Southern Sudan or in other locations. It also considered that clustering observers in committees would limit their ability to move freely from one referendum centre to another to observe the process.

The Regulations on the Role and Accreditation of Referendum Observers detail the code of conduct for such observers and provide for procedures to accredit them through the establishment of accreditation committees. In line with the Act the regulations do not provide for political party agents to observe the process.

39 Section 2 of the Act defines 'court' as 'the National Supreme Court, or the Supreme Court of Southern Sudan'. 
During the preparation of the regulations the commission held discussions with its international partners about allowing political party agents to observe the process and drafting regulations for this purpose. At this point the commission decided not to allow agents to observe the process at all, believing that their presence might generate confusion among voters and might be construed as interference in the voting process.

In the end, however, as a result of pressure from political parties, the commission decided to allow party agents to apply for the same accreditation as other domestic observer organisations. This decision, although, on the one hand, contributing to enhancing political confidence in the referendum process, raised doubts about clarity and a disregard for international standards of election observation, which prescribe different treatment for party agents from that accorded to international and local observer organisations.

\section{MEDIA AND ADVOCACY CAMPAIGN}

Chapter 5 of the Act is dedicated to Media Rules and Guarantees, with s 46(1) defining the principles of the referendum media programme by giving 'registered political parties and individuals ... the right to explain, express, disseminate and announce their views on the two referendum options through various media and information channels'. In addition, s 45(4) mandates the SSRC to establish an 'independent and impartial media committee to launch a media campaign for the education and enlightenment of the Sudanese people in general and the Southerners in particular on the referendum procedures'.

The SSRA includes only general principles for the conduct of the referendum campaign, conferring upon the SSRC the power to regulate it. ${ }^{40}$ This challenge was increased by the lack of a legal framework for media in Southern Sudan - the national broadcast media legislation in force in Northern Sudan was not applicable in the South. ${ }^{41}$

40 Section 7 of the SSRA provides that the different levels of governance shall commit to creating a conducive environment for conducting the referendum', inter alia, by providing an

a) appropriate environment and security conditions in order to prepare and organise the free exercise of the right to self-determination.

b) Freedom of expression for all the people of Sudan in general and the people of Southern Sudan in particular to enable them to dispense their views on the referendum through mass media or any other means.

41 The Press and Publication Act enacted for Northern Sudan in 2009 by the National Legislative Assembly in Khartoum was not applicable in Southern Sudan although the content of South Sudanese newspapers printed in Northern Sudan was subject to the strict control of the National Press and Publication Council. 
While s 46 stipulates that during the campaign period 'any government official or public authority shall treat all groups and individuals equally and with the utmost impartiality', the Act does not commit all state authorities to strict neutrality in their official capacities and the commission was not in a position to set up mechanisms to ensure the neutrality of the state-held media.

The SSRC appointed the Independent Media Committee, based at the commission's headquarters in Khartoum, ${ }^{42}$ a few days before the launch of the media campaign on 7 November 2010. However, the Media Campaign Regulations were only published on 13 December.

The regulations clarified the ambiguity of the use in the Act of the terms media programme and media campaign, specifying, in Regulation 5(a), that the Independent Media Committee had the power to conduct a 'public awareness and information campaign to inform Sudanese people in general and people of the Southern Sudan in particular about the referendum and its various processes'. In addition, Regulations 6, 7 and 8 gave the committee the power to accredit advocacy groups for the referendum campaign and Regulation 59(d) authorised it to receive complaints about the 'breach of fair and accurate reporting of the referendum campaign and any violation of the media code of conduct'. In the latter case there were doubts about whether the committee had the power to redress complaints effectively.

The regulations also contained specific requirements for advocacy groups or individuals and, in line with the Act, did not allow political parties which were not registered according to the provisions of the Political Party Act of 2007 to act as advocates. However, the commission decided to accredit such parties as well.

The campaign was conducted in both Northern and Southern Sudan, with the support of both governments, but with minimal or no respect for impartiality and the fair representation of both sides.

The commission's information campaign consisted of a few sensitisation events and the production, with the support of UNIRED, of brochures, newspaper advertisements, posters and items such as bracelets, bags, t-shirts and hats. The assistance and support of UNIRED in the information campaign raised concerns among commission members about the ownership of the process and the need to show the commission's independence at all stages of the referendum.

42 Initially Regulation 70 of the SSRC Internal Regulations of October 2010 had laid down that the Independent Media Committee should be based in Juba. This changed in the course of implementing the referendum process on the basis that situating the body in Khartoum would help build confidence among those parties which opposed the referendum. 


\section{AUDIT OF THE COMMISSION'S ACCOUNTS}

Section 21 of the SSRA provides for the commission's accounts to be audited by the National Audit Chamber (NAC) 'at the end of each fiscal year and at the end of the Referendum for submission to the National Assembly'.

In spite of the provision of s 64 of the Act that '[ $t$ ] he Government, the Government of Southern Sudan and the International Community shall fund and appropriate the necessary funds into the accounts of the Commission to fund its running costs and the costs of the referendum' the commission received direct funding only from the government of national unity and the government of Southern Sudan, while the international community supported it by means of donations in kind and technical assistance aimed at meeting all necessary requirements for the organisation of a credible and transparent referendum. ${ }^{43}$

It can be argued that $\mathrm{s} 64$ is void for vagueness because it imposes obligations on donors without taking into account their requirements and standards of transparency and accountability and without involving them in the drafting of the provision, therefore the lack of direct funding from the international community cannot be considered a violation of such a provision.

The responsibility for the organisation of the referendum rested with the CPA partners, and the international community, in supporting it, required accountability mechanisms with different standards from those set out in s 21 of the Act. Moreover, this provision raises several questions about the period during which the audit has to take place, the accountability of the commission for expenditure and the accountability of the bureau for the management of funds donated directly by GOSS. The Act also sets no time limit for the audit of the commission's accounts. ${ }^{44}$

In May 2011, after the presidency closed the accounts of the commission, the NAC indicated its intention to began its audit. In response, the commission asked for adequate time to present all its statements of account, including those for funds donated by GOSS to the bureau in Juba and the headquarters in Khartoum. However, the NAC responded that the audit would be limited to the accounts of the commission in Khartoum.

Funds donated by GOSS to the bureau and the commission are public funds and should be audited by the NAC in accordance with the abovementioned provision of the Act. Questions arise about how, practically, the NAC would be able to carry out such an audit. There seem to be only two possible ways in which it could do so. It must either request the commission's headquarters in Khartoum

43 The UN Development Fund for Women and the UN Development Programme donated small amounts to the SSRC's departments of gender and media for the voter information campaign.

44 Because the commission was only appointed on 30 June 2010 its accounts were to be audited by the NAC only once, at the end of the referendum. 
to produce a statement of the bureau's accounts - an option in which it appears not to be interested or it must authorise the Southern Sudan Audit Chamber (SSAC) to conduct the audit. If it takes neither of these steps it is unlikely that the funds of the SSRB will be audited in compliance with the provisions of the Act.

\section{CONSTITUTIONAL COURT CASES}

As indicated above, during the referendum various political parties, groups of lawyers, and tribes filed cases before the Constitutional Court in Khartoum alleging violations of the CPA and of the Interim National Constitution and Referendum Act.

The court heard five cases, dismissing four. One is still pending. The constitutional issues raised and under consideration include, inter alia, the timeframe for the conduct of the referendum, the composition of the SSRC and violations of the Referendum Act. The court declined to hear cases related to individual eligibility determinations and corrupt practices, as the appellants had not exhausted the remedies provided in the Referendum Act.

The case accepted by the court was not heard because the absence of Southern members of the court meant it was unable to gather the quorum of seven of its nine judges prescribed by Article 8(1) of the Constitutional Court Act. It is not clear whether the absence of the three judges was politically motivated..$^{45}$

\section{CONCLUSION}

'The time is very short. It will be a complete miracle to conduct the referendum in the short remaining period. However, I still believe that the miracle can happen,' said the chairman of the SSRC, Professor Mohamed Ibrahim Khalil, during his meeting with the first vice-president, and president of GOSS, Salva Kiir Mayadrit, at the end of October 2010.

The miracle happened. On 9 January almost all polling centres opened on time and they closed on 15 January, as prescribed by the Act. There were no particular security incidents and no complaints have been lodged alleging irregularities during the polling period.

On 7 February 2011 the SSRC declared the final results of the referendum on self-determination for the people of Southern Sudan. Of the 3851994 who voted 3792518 , representing 98.8 per cent of Southern Sudanese voters, opted for secession. On the same day the results were accepted and welcomed by President

45 In EUEOM 2011, p 19 it is explained that lawyers for the applicants in one of the unresolved cases wrote to the Constitutional Court arguing that the removal of judges was a breach of the CPA because it failed to provide the protection for which the Constitutional Court had been created. 
Omar Bashir, speaking on television, as the expression of the will of the people of Southern Sudan.

The referendum has been considered an example of the commitment, professionalism and transparency of all the parties involved - the commission, the international community, the GoNU, the GOSS and the people of the Sudan who participated peacefully. In particular, the parties to the Comprehensive Peace Agreement summoned up the courage and political commitment required to ensure that the process they embarked upon would conclude with the referendum, as stipulated in the agreement (UN SG Panel, 16 January 2011).

The challenges analysed in this study seemed insurmountable just a few weeks before polling began but neither these nor the few irregularities registered affected the integrity, validity and legitimacy of the process, which took place in a peaceful environment and was considered a remarkable operational achievement.

Fundamental to the success of the referendum was certainly the strong commitment of the CPA partners, the international community and the staff of the SSRC and SSRB. But commitment does not always lead to excellent and effective results.

In the case of the Southern Sudan referendum, in spite of the mistrust among the CPA partners and the problems with the agreement, the lack of clarity of the SSRA and the operational and logistical challenges, the following factors can be identified as responsible for the success:

- A solid, clear and uncontested legal basis for the exercise of the right to self-determination for the people of Southern Sudan. The recognition in the CPA of the right to self-determination, in spite of the interpretations related to the alternative modalities for its exercise, was clear and undisputed, as was the referendum question the SSRA copied from the INC and ICSS and the date of the start of the referendum. This clarity obviated misunderstanding about the interpretation of the results of the referendum.

- A well-defined mandate for the SSRC, its balanced composition and the clear division of tasks between the SSRC and the SSRB with respect to their roles.

- The SSRC's ownership of the process and its transparency and independence from both national and international counterparts.

- The clear-although broad-mandate of the Referendum Commission, together with its balanced composition, between Northern and 
Southern Sudanese commissioners, contributed to the transparency of the process and the consequent enhancement of trust among the parties.

- The commission also built trust through its efforts to maintain independence from both local and international partners, to ensure the ownership of the process and to inform the public constantly about the main achievements in the organisation of the referendum.

- The establishment of the SSRB in Juba, with a clear mandate, defined by the Act, also contributed to building confidence in the process, especially among Southern Sudanese, who did not perceive the referendum as being driven by Khartoum. Moreover, the presence of the bureau allowed for better operational and logistical planning of the activities for Southern Sudan.

- In spite of an initial lack of communication between the SSRC and the SSRB and some early difficulties the chairman of the SSRC and his deputy - as chairman of the bureau - made a serious effort to respect each other and required the same respectful behaviour from the commissioners and senior staff in both Khartoum and Juba. The positive attitude of the two leaders, who took no decisions and undertook no actions which could jeopardise the conduct of the referendum, improved the relationship between the commission and the bureau, a relationship which has been praised for being professional and respectful.

- Effective coordination and information-sharing mechanisms provided by the international community and the constant constructive dialogue with the SSRC. The international community played an important role in the success of the referendum. It managed to build trust among different parties, to keep the dialogue open with the commission even during the most difficult moments, and to face all crises constructively, without hindering the authority of the commission or the bureau or undermining local ownership of the process. The coordination and information-sharing mechanisms were effective and able to address challenges at operational, technical and political levels, allowing for the constructive participation of all parties involved in the referendum. 
- The commitment to the process of national counterparts.

- The peaceful attitude of the Sudanese people. The GoNU and the GOSS contributed to the creation of a peaceful environment for the organisation of the referendum, sending a message of peace to the people of Sudan. The people of Northern Sudan respected the choice of the Southerners and the people of Southern Sudan always respected the Northern nationals, peacefully awaiting the date on which they could exercise their right to self-determination.

The referendum set high standards for democratic participation processes in both the region and the entire world. The lessons learned represent an authoritative precedent to be followed in future similar contexts.

\section{REFERENCES}

Agok Declaration. 2003. 'Resolutions of the Ngok of Abyei People's Conference'. Preamble Part IA, IE, June 2-7. Rift Valley Institute Sudan Open Archive. Available at: www.sudanarchive.net

Assessment and Evaluation Commission. January 2010. Evaluation Report. Available at: www.aec-sudan.org/press.html

Carter Center, The. 14 February 2011 Statement on Counting and Tabulation Processes for the Southern Sudan Referendum. Available at: www.cartercenter.org/ resources/pdfs / news/pr/sudan-final-results-021411\%20.pdf

Collins, R O. 2008. A Modern History of Sudan. Cambridge: Cambridge University Press.

Council of Europe. 2007. Report on the Code of Good Practice on Referendum. Available at: www.coe.int

Democracy Reporting International (DRI). July 2010, Assessment of the Southern Sudan Referendum Act. Berlin.

Deng, F M. 2005. 'African Renaissance: Towards a New Sudan'. Forced Migration Review, November.

- 2010. Sudan at the Brink: Self-Determination and National Unity. Oxford: Oxford University Press.

Draft Interim Constitution of Southern Sudan. Available at: www.gossmission. org/goss/images/agreements/interim_constitution_southsudan_2005. pdf

European Union Election Observation Mission (EUEOM). 2011. Final report on the Southern Sudan Referendum 2011. 
International Court of Justice. 2010. Accordance with international law of the unilateral declaration of independence in respect of Kosovo. Advisory Opinion, 22 July.

International Crisis Group. March 2006. Sudan's Comprehensive Peace Agreement: The Long Road Ahead. Nairobi/Brussels: Africa Report 106.

International Legal Resource Center. 2010. Legislative Assessment of the Referenda on Southern Sudan and the Abyei Area. Washington, DC.

Johnson, D H. 2004. The Root Causes of Sudan's Civil Wars. Oxford: International African Institute in association with James Currey.

Johnson, H F. 2011. Waging Peace in Sudan: The Inside Story of the Negotiations That Ended Africa's Longest Civil War. Sussex: Sussex Academic Press.

Joseph, S, J Schultz \& M Castan. 2005. The International Covenant on Civil and Political Rights: Cases, Materials, and Commentary. 2nd edition. Oxford: Oxford University Press.

Mitchell, C R. 1989. Conflict Resolution and Civil War: Reflections on the Sudanese Settlement of 1972. Centre for Conflict Analysis and Resolution, George Mason University, Working Paper 3.

Nyaba, P A. 2000. The Politics of Liberation in South Sudan: An Insider's View. Kampala: Fountain Publishers.

Office of High Commissioner for Human Rights. 13 March 1984. CCPR General Comment No. 12: The right to self-determination of peoples Art 1.

__ 1 November 1999. Concluding Observations of the Human Rights Committee on Morocco. CCPR/C/79/Add 113.

Seidner, S S. 1982. Ethnicity, Language, and Power from a Psycholinguistic Perspective. Bruxelles: Centre de Recherche Sur le Pluralinguisme.

Shinn, D H. 2004, 'The Addis Ababa Agreement: Was it Destined to Fail and Are There Lessons for the Current Sudan Peace Process?' Annales d'Ethiopie 20.

Southern Sudan Centre for Census Statistics and Evaluation. 2009. The Statistical Yearbook for Southern Sudan. Juba.

Southern Sudan Referendum Commission. October 2010. Legal and procedural questions and answers. Available at: www.ssrc.sd/SSRC/ newsphoto / 0843ef 2819af0136b4659d793e2cbafaCritical\%20Questions\%20\&\%20Answers.pdf

Southern Sudan Referendum Commission. October 2010. Eligibility Criteria. Available at:

www.ssrc.sd / SSRC/ newsphoto/5db4e4b1764a08c3857ba46d70e19be7Eligibilit $\mathrm{y} \%$ 20Criteria.pdf

Thomas, E. 2010. Decisions and Deadlines: A Critical Year for Sudan. London: Chatham House report.

United Nations Secretary General Panel on the Referendum. 2011. Press release, 16 January. 
Van Walt van Praag, M C \& O Seroo (eds). 1998. Report of the international conference of experts held in Barcelona from 21 to 27 November 1998. Barcelona: UNESCO, Division of Human Rights Democracy and Peace.

Verjee, A. 2010. Race Against Time: The Countdown to the Referenda in Southern Sudan and Abyei. London/Nairobi: The Rift Valley Institute

\section{Court case}

Permanent Court of Arbitration. 22 July 2009. Arbitration between the Government of Sudan and the Sudanese Peoples' Liberation Movement/Army on Delimiting the Abyei Area. Available at: www.pca-cpa.org/ showpage.asp?pag_id=1306

\section{Interview}

The Hon Paolino Wanawilla Unango, Deputy Minister of Justice for the Republic of South Sudan and Commissioner of the South Sudan Referendum Commission. 